THE BACTERIOLOGICAL ASPECTS OF THE PROBLEM OF NEUROPATHIC KERATITIS. BY

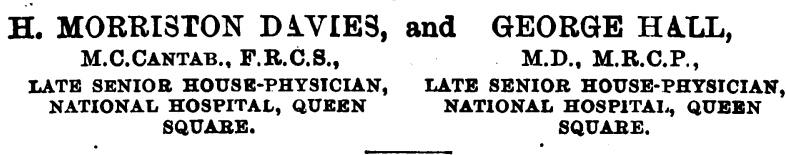

I.

THF intlmate relationship of neuropathic keratitis to digturbance of the filth nerve and Gasserlan ganglion has resulted in the pathology of this lesion being regarded in a very different light from that of other corneal affections, the eye changes in all cases belng considered as secondary to the morbid condition or disturbance of the Gasserian ganglion. That the cause of the disease is difficult to elucidate is seen by the many hypotheses which have from time to time been propounded as the solution to the question, from the number of opponents who have taken the field on one or the other of the sides, and also from the manner in which these have at various times altered or modified their vlews. Before, then, we can bring forward the result of our investigations it is necessary that the several hypotheses should be mentioned. But as Wilbrand and Saenger ${ }^{1}$ have set out the detalls of the work and controversies on this subject 80 fully we need only briefly enunciate these hypotheses and give in outline the arguments for and against.

\section{The PURmix Trophic Hrpothresis.}

Magendie $^{2}$ showed that neuropathlc keratitia occurred $n$ animals after section of the Gasserian ganglion, and asserted that trophic fibres for the cornea travelling in the fifth reached their destination by the cillary nerves. Further, by experiments conducted by Magendie and Claude Bernard, ${ }^{3}$ and later still by Gaule, 5 it was shown that when the Gasserian ganglion was cut across, especially in its anterior part, neuropathic keratitls developed rapldly, but that when the fifth root was divided, although corneal anaesthesia was produced, keratitls elther did not supervene, or else was late in onset and mild in character. This fact is supported by the clinical observations of Bernbardt ${ }^{6}$ and Erb, ${ }^{7}$ also by v. Graefe, ${ }^{8}$ who. regards the lessened secretion of tears, a necessary result in his opinion of ext!rpation of the Gasserian gangllon, as only accelerating the condition. These trophic fibres were thought by Gaule to be connected with the numerous cells which he found in the intracranial portion of the ramus ophthalmicus in rabbits.

\section{The Trophic Tradmatic Hypothesis.}

(a) Trophic with Central Irritation.

Wilbrand and saenger ${ }^{1}$ consider that trophic nerves play a considerable rôle in the preservation of the eje, but do not believe that the preservation or destruction of these fibres alone determines the presence or absence of keratitls. They support the view that whilst the loss of trophic fibres is the predisposing cause, the exclting cause depends on central irritation of the roots of the nerves or of the ganglion cells. In those cases of trigeminal neurectomy of Krause's ${ }^{9}$ which developed neuropathic keratitis the extreme severity of the operation entalling rupture or irritation of the trigeminal branches and the loss of the trophlc fibres were in their opinion the etiological factors, else, had it depended only on the geverance of the cornea from its trophic nerves, all the cases would have developed keratitls. By this means also they explain those cases of trophlc corneitis, as they term the affection, associatied with Impaired or Increased sensitiveness of the cornea.

Parsons, ${ }^{10}$ referring to the work carried out by Head in conjunction with Sherren, ${ }^{11}$ Rivers, ${ }^{12}$ and Thompson, ${ }^{13}$ dealing, with the paths of efferent Impulses in the peripheral nerves and cord, and to the work of Bagliss, ${ }^{14}$ in relation to antidromic impulses in afferent nerves, shows that the absence of protopathic sensation favours bed. sores; that on the recovery of these fibres decubitus tends to heal rap'dly; and also that antidromic fibres can be experimentally excited in a nerve of a cat after that nerve has been divlded and reunited. "Hence," ho continues, "it may be considered proved that the power of produclag, changes in the skin of the periphery is a function of fibres which run in the protopathic system." Theese fibres may conduct impulses antidromal in character the stimulation of which by some central irritation produces " a deleterious effect upon the nutrition of the perlpheral organs." That the neuropathic condition of the eye is due to similar factors appears to Parsons as probable, and for these reasons he considers that the trophic-and.central-trawmatic hypothesis "explains better than any other all the diverse clinical facts which have accumulated."

Flemming, ${ }^{10}$ another supporter of this hypothesis, states. in favour of the trophic element that other trophic changes may be observed in fifth nerve leslons, and in support of the necessity of the added factor-central irritation-gives cases to show that when neuropathic keratitis develops the filth nerve has been only partially divided. In conclusion he says "that the nutrition of the eyeball is directly dependent on the integrity and nutrition of certain nerve fibres contalned in the Gasserian ganglion and ophthalmic nerve, and that irritation of these fibres leads to those changes in the nutrition of the cornea which are regarded as neuropathic keratitis."

\section{(b) Trophic with Peripheral Irritation (other than} Organisms).

Samuel, ${ }^{16}$ from observations on other parts of the body, Imagines a system of centripetal and centrlfugal trophic nerve fibres, whose centre be places in the Gasserian ganglion, the disturbance of which renders the eye less capable of resistance, so that slight Irritations of the cornes which a normal eye would withstand without Injurs are capable of setting up thls condition. Büttner's found that a glass shield or a wire net strapped in front of the eje was a preservative measure against traumata which a normal eye could withstand without injury. He conslders the loss of sensation an unimportant factor.

\section{The Vasomotor Hypothesis.}

Spalitta ${ }^{18}$ is the chief supporter of this hypothesis. He. bases his conclusions on certaln experiments in which, after removing the Gasserian ganglion, he noticed very marked vaso-constriction of the vessels of the eye, especially in the pericorneal area, and also necrosis of the cornea. This necrosis he attributed to the vaso-constriction. When, however, he removed the cervical sympathetic ganglion and subsequently the Gasserian ganglion, the vaso-constriction of the uncomplicsted Gasserian ganglion paralysis could not be effected and keratitis did not develop.

\section{The Vasomotor Tradmatio Hypothesis}

Schiff ${ }^{19}$ holds that, following the excision of the Gasserian ganglion, there is a hyperaemla which lasts for about twelve days. After this time it begins to subside, appearing only at increasingly long intervals till it finally disappears. Occasionally, however, the byperaemla persists, and only when this occurs can external injurious mechanisms come into operation. Seydel, another upholder of the hypothesie, reports his observations in 6 cases. In 3 of these there was an uncomplicated trigeminal paralysis, and no evidence of neuropathic keratitls was found. In the other 3, in addition to the trigeminal paralysis, there was disease of the sympathetic, as was evidenced by the enophthalmos, narrowing of the palpebral fissure, and myosis. All there cases developed keratitis. Seydel's view is that vasomotor disturbance, anaesthesia, and sympathetic paralysis are all necessary as predisposing causes, and that slight traumata of the cornea in the centre where the nutrition is least good are the exciting cause, a necrosis associated with in flammatory aymptoms belng the first change produced.

\section{The Porehy Tradmatio Hypothests.}

Snellen, Senftleben, ${ }^{21}$ and Gudden ${ }^{22}$ attempted, : by experimental Investigation. to prove that when the eye was kept carefully protected, as by a shleld or by sewing the lid s together, neuropathic keratitis never occurred. They held that animals, owing to the ansesthesis of the part, were not so careful in avoiding obstacles; and that foreign bodles gaining admittance were not 80 promptly expelled as their presence was not recognized. Caees of lagophthalmos associated with paralysis of the fifth are given, and cases also ctted of paralysis of .the fifth and ptosls without neditopathic changes. 
6. The Drasiccation Hypothesis.

Thls is supported by Feuer, ${ }^{23}$ Hippel, ${ }^{24}{ }^{25}$ and Ollendorf, ${ }^{26}$ who consider that after trigeminal neurectomy there is a marked dimination in the secretion of tears, and that there is also a great lessening in the Irequency of blinking on the affected side-a diminution more evident in animals than in man. As a result of these the part of the cornea exposed in the palpebral fissure becomes dried, and necrosis results. The necrosed part then acts as an Irritant, inflammation sets in, and the slongh is expelled. Protection of the eye by a shield or by stitching the lids together necessarily diminishes the evaporation and prevents the onset of neuropathic kera!itis.

\section{Criticism of the above Hypothests.}

Before proceeding to the last hypolhesis- the mycoticsome of the chief arguments against the views above mentloned must be brought forward.

It is a recognized fact that, especlally in human beings, after trigeminal neurectomy only a certain proportion of the patients develop neuropathic changes of the cornes Wilbrand and Saenger give the proportion as a third, and our own statistics, as will be seen later, are almost the same. Now if the loss of the trophlc fibres were the cause of the neuropathic condition, the eye should always be affected after removal of the ganglion. Wilbrand and Saenger attempt to overcome this argument by assuming either a greater power of resistance of these fibres or tha those passing to the eye have escaped injury. In practlaally all our cages, however, the Gasserian ganglion was completely removed, together with the intracranial branches of the avalsed sensory root. Ranvier denies the existence of trophic fibres in that as a result of a series of experiments in which the nerves to the cornes were cat he has never notlced any alteration in the mutritlon of the part. Certainly aseptic wounds heal as readily in an anafsthetic as in a normal cornea. Again, if the keratitis is dependent on the loss of trophic nerves, how is it that when properly treated the condition clears up?

The existence of tropblc changes other than in the eye as a result of lesions of the filth nerve is Irequently brought forward. In 50 cases in whlch the Gasserian ganglion had been removed we bave only once noted any change other than the corneal. This was in a woman who four years previously had had an extremely severe attack of herpes on the right side, after which in the ares of dis. tribution of the right ophthalmic division there was intense pain, anaesthezia bounded by a zone of hypergesthesia, loss of hair, loss of the + yebrow and eyelashes, and patches of leucoderma over the upper part of the torehead.

The part played by trauma in the production of this pathological condition of the cornes is only supported by one out of 50 cases of trigeminal neurectomy which we have observed. This patient (A. H.), a man aged 26 , remained free from all eye trouble for twenty months after hls operation. During thls interval he worked in brick fields. At the end of twenty months his eve showed a mild degree of karatitis, but after a few weeks of treatment cleared up. Six months later he again attended for keratitis. On both occasions he thought that the trouble had originated from some brick dust which had Initated his eye. The second attack cleared up after seven weeks, and for the last two and a half seare, although he has continued his work without other precantion than occasionally bathing the eye, the cornea is quite healthy and shows only some old opacities.

We have observed that in nesrly every case where nenropathic keratitis is going to appear it will be seen first during the stage of convalescence. If the patient remains free during thls period only very exceptionally does the condition manifest itself at a later time. Further, in some of the cases we have seen, during the first few days, islands of loss of epithelium on the cornea without any indication of neuropathic keratitis developing either then or later.

The following case affurds argaments against both the trophic-and-peripheral-traumatic and the trophic andcentral-irritation hypotheses :

The patient had an endotheliom3 of the leit Gasserian ganglion; the tumour and ganglion were removed. The resulting ansestliesle of the area sapplied by the ophthalmio division was not complete. The outer end lower portion of the oornea was ansesthetilo, but over the upper and inner surface there still remained slight senslbillty for touch. Within a very short time the patient had a recurrence of the growth which eventually involved not only the cavum and the ou ends of the peripheral branches of the fifth but also the sensory root, causing great pain in the trigeminal area. Infeoted glands appeared at the angle of the jaw and over the parotid on the same side, and there was complete peripheral paralysis of the left facial nerve. Despite the lagophthalmos, and on two occasions a superficisi loes of epltheliam of the cornea; despite occasions 8 superficial loes of epithelinm of the cornea ; despite
the Irritation round the peripheral branches (and the sensory the irritation round the peripheral branches (and the sensory
root) of the divided fifth, there was never at any time any indication of neuropathic keratitis.

We have already referred to the suggestion made by Parsons that neuropathlc keratitis develops because the "afferent tract is still open, bat an irritative lesion has set up abnormal antidromlc impulses in the protopathic system." In the case just mentioned there was evidence of a partial division only of the sensory fibres of the cornca and of an irritative lesion in the lorm of a malignant tumour surrounding the afferent tract. Here all the factors necessary on such a hypothesls for the production of neuropathic keratitis were present, yet neither in this nor in the following somewhat simllar case did the cornea show any pathological change.

W. $P$ suffered from neuralgis of the first and second divisions of the right trigemingl for five years His Gasserian ganglion was removed but, owing to the strength of the adbesions, the anterior and inner part of the ganglion had to be left attached to the ophthalmic branch. The patlent made an uneventful recovery. Two years later he was readmitted suffering from a recurrence of pain in the first division. A note made at that time says that his eye was perfectly normal, and the cornea quite clear. There was no absolute loss of sensation of the cornes or conjunctiva, but the corneal reflex was sluggish. At the recond operation the osvam Meckelii was founa to be empty, but " $a$ - little blunt dissection further on through some tissue which appesred to be of inflammatory on through some tissue which appeared to be of inflammatory origin revealed a nerve ts unk distinctly larger than the normal sixth nerve, and running outwards over the edge of the petrous This was removed. No weakness of the external rectus resulted, and the patient was free from his pain. The cornes also became completely anaesthetio. At no period before or sabsequent to the second operation, which was nearly five years ago, has there been the slightess traç of keratitis.

After section of a nerve, degeneration begins to appear In the peripheral part withln the first twenty.four houre, and is complete in twenty days. Since the pablication of Halliburton's Oliver. Sharpey lectures ${ }^{27}$ we may now take it as certain that regeneration of a cut nerve orlginates from the central end, and that towards altimate reunion and complete regeneration the peripheral segment contributes practicaliy no help. If, then, after excislon of the Gaskerian ganglion, keratitis is due to an irritative stimulus produclng antidromic impulses, when not seen within the first twenty days it should not appear at all. How, then, did it occur in the case of A. H, already mentioned, in whom there was no indication of $\mathrm{k} \in \mathrm{aratitis}$ till twenty months alter the removal of the ganglion?

Certain authoritles maintain that the anaesthetic condition of the eye prevents it from reacting to the stimulus of foreign bodies, which are thus allowed to remain and to cause trauma. But it must be remembered that in over 60 per cent. of the patients who for years are exposed to this risk no such deleterious consequences appear. On the other hand, cases have been reported of keratitis in ej6s which are stnsitive or even hypersensitive, and which hould therefore bave been able to recogn'ze immediately the presence of forelgn particles.*

Angelucci ${ }^{28}$ was unable to corroborate Spalitta's experiments in connexion with the vaso constriction hypothesis. On the contrary, by ligaturing the common carotid and at the same time excising the cervical sympathetic ganglion he produced a most marked degree of vaso.constriction without neuropathic keratitis $\varepsilon$ upervenlng. The occurrence of vasomotor fibres in the fifth nerve has not indeed been proved. Krause states that the eye after excision of the $G$ seserian ganglion shows no devlation from the normal ; nor bave we been able to find any dilatation or constriction of the vessels either directly after or at periods extending up to ejght years after the neurectomy. Turning now to the desiccation or zerotic hypothesis, one of $\mathrm{us}^{29}$ as the result of repeated observatlons of 30 cases of trigeminal neurectomy. has found that

* Wilbrand and Saenger hare collected four cases of neuropathic keratitis in patients who had some lesion of the trigeminus but whose cornea was sensitise. 
there is no difference in the secretion of tears or in the rate of blinking of the eytlids on the affected side. Krause, ${ }^{\theta}$ however, states that the secretions of the lacrymal gland are delayed. In the case of endothelioma of the Gasserian ganglion with associated homolateral paralysis of the facial nerve mentioned above, the rate of onset of the flow of tears was distinctly delayed, and in addition only very slight and infrequent winking movements occurred on that side. Yet, despite this, keratitis did not develop.

Senftleben found that if an animal in which a trigeminal neurectomy had been performed was tied down on its side with the anaesthetic ese uppermost so as not to hinder evaporation, the cornea remained perfect]y healthy, and keratitis did not develop untll the animal was allowed to run about. Farther, keratitis has been seen in patients who have had the eye protected from evaporation both by ptosis* and by careful bandaging.

\section{The Mrcotio Hypothesis.}

Turner, ${ }^{30}$ in conjunction with Ferrler performed a serles of experiments on animals. Two out of the eighteen cases showed destruction of the cornea and pan ophthalmitis from septic infection; two also exhibited progressive corneal opacities. As a result of experimental irritation of the cornea, a transitory inflammation followed by healing was produced. From this Turner considered that Irritation of the first branch of the fifth exerclsed no neuropathic effect upon the cornea, and attrlbuted the disturbances of this part to an inflammatory irritant, the result of a septic infection. This view Krause, from his clinical observations, tends to support, and he believes that atter removal of the Gasseriau ganglion there exists a reduced power of resistance to inflammatory influences. Baylock, in h/s experiments, produced traumatic loss of the epithelium of the anaesthetlc eye, thus renderlng it possible for microorganisms to enter and to form the exclting caus e of the keratitis. Whllst Hippel, who at first did not regard micro-organisms as an etlologi cal factor, later thought it very proballe that bacterla play an important rôle in the

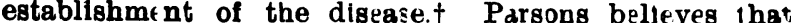
organisms are important only in the more advanced stager.

As the arguments against all these hypotheses other than the mycotic appeared to us to outweigh those in their favour, and recognizing, moreover, the great part played by micro-organisms in most progressive and relapsing inflammations, we declded to attempt a further investig 3 . tion of neuropathic keratitis from the bacterlological aspect in the bopes of finding some organism which was constantly present only in those eyes which developed keratitis after trigeminal neurectomy, and which by experlmental inoculation into monkeys would produce the condition.

The results of our researches we shall now record. From the clinico-pathological aspect they appeared to us to be very encouraging, but our experimental work carrled out with the desire to corroborate the former, whilst in some respects it supports our earlier investigations cannot be regardt $d$ as conclusive.

The whole of the experimental work has been performed for us by Sir Victor Horsley, and we cannot sufficiently express our gratilude to him for his kindness in dolng it and for the time he has devoted to this piece of work.$$
\text { II. }
$$

BACTERIOLOGIOAL INVESTIGATIONS.

Our investigations have been based on the examinations of 21 clinical cases. All these cases had the Hartley-Krause operation performed for trigeminal neuralgla; 11 of them developed neuropathic keratitis, whilst the other 9 up to the time when they were last seen, showed no affection of the cornea. These patients have bsen under observation for periods ranging between five days and five years.

In one case the keratitie, which had been neglected by the patient, had progressed to a condition of hypopyon and phthlsis bulbi and the eye was excised. Mr. Parsons,

* In fifty-four cases of ptosis associated with paralysis of the fifth nerve collected by Wilbrand and Saenger, twenty-two had neuropathic keratitis.

t Hippel describing, however, the results of the pathological examination of an eye affected by neuropathic keratitis, says Mrroorganismen irgend welcher Art konnten in der Cornea be who performed the operation, most generously gave us the pathological specimen, our findings on which and on four eyes taken from monkeys who had developed neuropathlc keratitls will be recorded in due course. In addition we have made a bacteriological examination of twenty-two normal eyes.

Finally, Sir Victor Horsley undertook by a series of operations on animals-8 monkeys, 1 cat, and 2 guinespigs-the Investigation of the pathogenlc properties of that organism which we found to be constantly present only in the eyes of patients affected with keratitis.

We wish to express our thanks to the following gentlemen, who have very kindly allowed us to examine the cases under their care: Sir Victor Horsley, Mr. Flemming and Mr. Parsons, Sir William Gowers, Dr. Ormerod, Dr. Risien Russell, and Mr. Armour. Also to Dr. Thiele for inn ulating and making post-mortem examinations on two guinea-pigs.

Bacteriological Examination of Twenty.one Clinical Cases.

In the earlier cases we were able to obtain cultures from the eyes only after removal of the Gasserian ganglion, but in most of the others we made bacteriological examinations both before and after the operation.

The cultures were taken from the conjunctival sac of the eye on the side of the trigeminal neuralgia or neurectomy, from the interior of the nostril on the same side, and in most cases from the conjunctival sac of the opposite eye. They were grown on agar-agar. After twenty-four to thirty-six hours' incubation, the colonles were examined

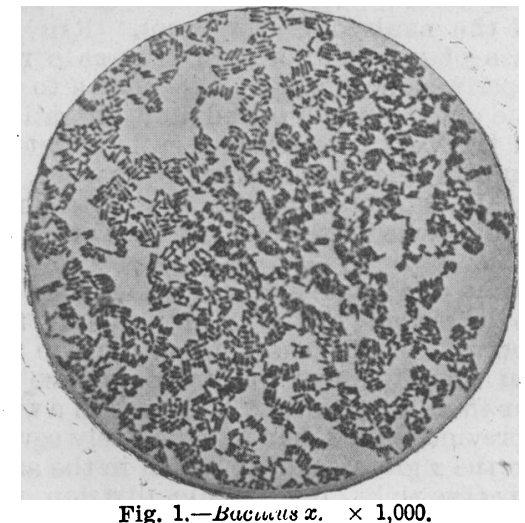

macroscopically and microscopically. When a colony was not pure it was plated out and separated into its various constituents, each of which was again subcultured on to agar agar.

In a few cases blood serum was used. The pure cultures were then individually investigated. In practicalls all the cases Staphylococcus aureus was found; less trequently staphylococcus albus, streptococcus, pneumococcus, xerosis and proteus. But there was also one other bacillus which we found only in those eyes which showed neuropathic keratitis. This organism, of which the following is an account, we shall refer to as Bacillus $x$.

\section{Description of the Organism.}

The organlsm is a short thick baclllus (about $2.0 \mu$ lon's. by $0.6 \mu$ thick) with rounded ends, frequently arranged in pairs, short chains and parallel groups (Fig. 1). In structure it is homogeneous and shows no evidence of spore formation. It is non-motile and has no flagella. It stains with all the ordinary dyes and gives a positive resction with the Gram method. It grows readily on all the ordinary media.

On agar.agar it forms a thick yellowish-white succulent growth with irregalar rounded marging.

On serum the growth is similar but not so profuse.

Gelatine-stab cultures show liquefaction only after some weeks without gas formstion.

On potato the organism forms a profuse opaque growth of a dirty cream colour.

In ordinary peptone broth a uniform.turbidity is produced, but no indol reaction can be obtained.

In litmus milk a fine coagulum appesrs, and in the early days an acid reaction which subsequently becomes strongly alkeline.

In neutral.litmus broth (glucose) there is no gas formar tion.

We have repeated the examination of the cultura) properties of this bacillas mang times, and our results; 
which have been constant, have also been corroborated by independent investigations. On this account, although further investigation is undoubtedly necessary, we feel justified In looking on these characterlstics as fairjy definite.

It would appear, then, that this organism belongs to the group of pseudo-diphtheria bacllli, and Its characteristics agree very closely with those of that form known as the pseudo-diphtheria bacillus of Loeffler.

The $x$ bacillus is very difficalt to distinguish from the pseudo-diphtherla organlsm, bat the following three factors help in the differentiation: The $x$ baclllas shows occasional granule formation, gives no naked-eye growth on potato, and does not render bouillon turbid.

\section{Clinical Cases.}

Of the 21 cases under observation, in all of which the Gasserlan ganglion had been removed by the HartleyKrause method, 11 were suffering or hsd suffered at some previous time from neuropathic keratitis.* In 9 of these patients we were able to take cultures from the eye and nose on various occasions when the eye trouble was in an active condition. The growths all showed, in addition to staphylococei and occasionally streptococci, pnenmococsl, $x$ erosis, and proteus, Bacillus $x$. From 6 of the patients cultures were obtained at various periods after the cornea had healed (J. G., 2 years ; A. H., 7 months; M. H, 3 months; C. W., 2 months; V. E., 2 months; E. G., 5 weeks). None of the colonies except those grown from the nose of $A$. $H$. and from the eye of M. H. showed the presence of Bacillus $x$. The latter patient, from whoseconjunctival sac the bacillus could still be recovered, had another ontbreak of neuropathic kerattis nine months later t The absence of Bacillus $x$ after the complete sub. sldence of keratitis was moreover shown oy our observations on the patient J.J. This woman had the Gasserlan ganglion removed in December, 1902 . A very
severe attack of keratitis followed in January, 1903 ; her eyelids were then sewn together, and kept united until April, 1904. Three daps aiter they were andone there was a fresh outburst of keratitis. The lids were reunited until March, 1905, but the separation of them then was agaln immediately followed by a recurrence. This was less severe than the prevlous ones, was trested withon closure of the lids, and cleared up within two months. In March, 1905, cultures showed staphylococci. and Basillus $x$. In November of that year, although the eye was still clear, the same organism was found. During June, 1906; there was a fresh though very slight outburst of keratitis, which soon subsided. Cultures still gave the same results. In January, 1907, however, only staphylococci and proteus were obtained. There has been no return of keratitis since this time.

Ten batients on whom bacterln]ogical examinations * This must not be regarded as in any way representing the true proportion of cases which develop keratitis after trigeminal neurecComy. We have the notes on 50 patientz on whom this operation was cime or another after the neurectomy.

$t$ This patient was then unfortunately too ill to corre and see us. were made (in seven both before and after the operation) have never suffered from any corneal affection consequent on the excision of the ganglion. The cultures from these cases contained staphplococcl, streptococcl, pneumococei, and xerosis, but no evidence of Bacillus $x$ was found except in those growths taken from the eye and nose of 8 . F. before the removal of the ganglion. Thls patient, however, died of meningitis five days after the operation; hls lids had been stitched together all the time, and no keratitis had developed. These facts may be put in tabular form thus :

\begin{tabular}{l|c|c|c}
\hline & $\begin{array}{c}\text { No. of } \\
\text { Cases } \\
\text { Examined }\end{array}$ & $\begin{array}{c}\text { Presence } \\
\text { of } \\
\text { Staphylo- } \\
\text { coccus. }\end{array}$ & $\begin{array}{c}\text { Presence } \\
\text { of } \\
\text { Bacillus } \\
x .\end{array}$ \\
\hline $\begin{array}{l}\text { Cases with neuro- }\left\{\begin{array}{l}\text { Acute stage } \ldots \\
\text { pathic keratitis }\end{array}\right. \\
\text { Cases without neuropathic keratitis }\end{array}$ & 9 & 9 & 9 \\
\hline$\dagger$ & 9 & $1^{*}$ \\
\hline
\end{tabular}

* This case developed another attack of keratitis later.

the case of the patient who showed the presence of the $x$ stitches were taken out of the eyelids) without developing keratitis, is purposely omitted.

We have had the opportanity of making a pathological examination of one human eye which was excised by Mr. Parsons owing to the advanced state of the neuropathic keratitis and assoclated phthisis bulbl. There was an extensive ulcor occupying a large part of the surface of the cornea. As soon as the eye was exclsed a culture was made from the surface of the ulcer, but no growth was obtained $\ddagger$ Cultures were also taken from the anterior and posterior chambers, the vitreous and the cut end of the optic nerve, but In every case the result was negative. A strip of the coats of the eye, includIng part of the cornea and the ulcer, was hardened, embedded in paraffin, and sections were cut and stained by several of the most common methods. Among the eplthelial cells at the edge of the ulcer numerous masses of staphylococel can be eeen. The largest clamps are to be seen along the edge itself, and they diminish rapidly in size as the healthier parls of the cornea are approached. Scattered among the staphylococci, and lying in between the eplthellal cells, a few $x$ bacilli can be detected. We have not, however, been able to corroborate the presence of the $x$ bacillus among the cells of the cornea in the eyes of the four monkeys whlch developed keratitie.

It would seem, then, that whatever part the Bacillus $x$ plays in the inltial stages of neuropathlc nlceration, once the process is established the staphylocoeci carry on the work of destruction. Nor is there any evidence to show that at this stage the tissues of the nearopathic eye react to the destructive processes of sepsis in any. way different from that $\mathrm{In}_{\text {-which reacts an }}$ $\epsilon$ ye the nerve supply of whioh is intact.

Wilbrand and saenger consider that a third of the patients who have had a lesion of the trigeminus or extirpation of the Gasserian ganglion auffer from neuroI A culture taken from the conjunctival sac on the previous day showed the Bacilus $x$. After this the eye
irrigated to ensure tbe asepsis of the operation. 
pathic keratitls. Oar own statistics, based on the notes on 50 patients, work out at a proportion of 36 per cent. It seemed to us that if the keratitis was produced by an organism which had a speclal pathogenic power on eses the sensibility of which had been in some way impaired, and that 36 per cent. of such people developed the corneal lesion, we might encceed in discovering the organism in about the same proportion of normal eyes. For thls reason, therefore, we made an examination of the cultures obtained from twenty-two normal eyes. All the cultures showed staphylococci, and in seven out of the twentytwo the Bacillus $x$. was also found. A curlous point was noticed : 15 of the cases chosen were hospital pstients; the remaining 7 were resident officers in the same institution. The seven cultures which showed the presence of the Bacillus $x$ were all obtained from the hospital patients.

\section{EXPRRIMHNTAL INVESTIGATION.}

The Bacillus $x$. obtained from a patient who was suffering from neuropathic keratitis was placed in the right conjunctival sac of three monkeys, a cat, and two guinea-pigs, to see if any pathological changes could be produced on the ncrmal eye. At the end of a month all the eyes were perfectly healthy. The subsequent experiments on these monkeys will now be glven in faller detall:

Rhesus 1. - A culture taken from the right eye on April 3rd, 1906 showed staphylocoscus and the presence of the xerosl bacillus. On the same day the right conjanotival sao was inoculated with the Bacillus $x$, obtained pnre by subculturing from colonies grown from the eye of $J$. J. Tae next day this organism, together with staphylococei, was found in the conjunctival sBc. The right eye remained healthy during the resi of the animal's existence. On April 6th the left eye was closed by sutning the eyelids, and sir Victor Horsley extirpated the left Gasserian ganglion. Three days later the stitcbes cutting out, the eye opened, and the cornes was seen to be quite healthy, but the next morning keratitis was already present and making rapld progress. A culture taken on this day showed staphylococol and an abundance of the $x$ bacillus. By the $15 \mathrm{th}$ an anterlor staphyloma had formed with prolapse of the Irls; and on the 30tn, when the animal we killed, there was only the shrunken cillapsed ejebsll to be seen between the closing lids. Cultares were taken on growths of the Bacillus $x$ and of Staphylococcus aureus and albus were obtained.

Rhesus 2 - The right conjunctival sac was jnocnlated on April 3 rd from the same tube as that osed for Rhes is Caltares taken from the eye on this day (before inocnlation) and on the 4 th showed only staphylococol. Sir Victor Horsley removed the left Gasserian ganglion on April 7th, baving prevlously stitched together the lids of the left eye. Two days later the stitches had cut out of the lids, and the cornes was seen to be healthy. There was no conjunctival reflex. On the 18th the left ecnjunctival sac was inoculated from the same tube as previoosly. No change had taken place bo the 28th, and the conjupctival s8c ws therefore inocalated from the discharge from the left eye of Rhesus 1 . This was again repeated in two days' time. On May 2nd there was some repeated in two days' time. On May 2nd there was some
dried discharge round the inner canthus which had increased by the 5 th, but the cornea remained clear. Cultures taken from the conjunctiva grew only staphylococous.

Rhesus 3.-The right conjunotival sac. which contained only staphylococel, was incculated on April 3rd, 1906, with th Bacillus $x$. On Aprll 7th, the left eye was closed by stitching together the lids and the left Gasserian ganglion removed by sir Victor Horsley. Four days later the eyelids were undone, and the cornea soperred dry bat otherwise healthy. From a culture then taken staphylccoccus and the xerosls baclllus were obtained. The following day there was xerosis baclllus were obtained. The following day there was condition was only transient. On the 18th slight pin-point alceration was observed. The conjunctival sao was inoculated on that day from an old growth of the Bacillus $x$ The next day the ulceration showed some progression, but by the 23rd the eye had recovered. On the 28th the conjunctival sac was inoculated with the discbarge from the eye of Rhesus 1 Two days later distinct cloudiness of the cornes was evident; the cloudiness increased, punctiform kerstitis and a trisident; ulcer appeared. On May 5th the monkey was killed, and the condition of the eyeat that time is shown in the accompanying photograph (Flg. 2). Cultures taken bofore death produced a copious growth of the Bacillus $x$.

Rhesus 4 and 5 , and Bonnet 3.-In Rhesus 4 the Bacillus $x$ was found on the conjunctival sis before the operstion. In Rhesus 5, growths of Staphylococcus albus only could be obtsined; whilst in Bonnet 3. Staphylococcus aureus exlsted. After the operation for the extirpation of the ganglion in these three cases the cornes was found to be still sensitive. No keratitis appeared elther 1 mmediately after the operation or aft:r iroculation with pure cultures of the $x$ bacillus.
Bonnet. 1-No culture was made before the neurectomy, On May 19th the loft Gasserian ganglion was removed, but the eye was not closed Koratitis was already present on the eye was not closed. Keratitis was already present on the following day, and caltures taken on the 22nd and 28th, by. of staphylococoi and of the $x$ bacillus.

Bonnet 2 -The monkey had the $x$ baclllas in its eye before the operation on May 28 th. Keratitis appeared four days after the exolsion of the left Gasserian gapglion on the day after the stitches cut out of the eye. By Jane 6th the keratitis was far advanoed, and cultures showed staphylococof and the $x$ baclllus. These were separated by plating. A pure cultura cf stapbylococel was obtained and injected into

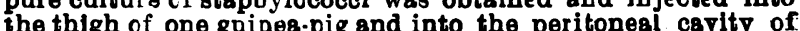
the thigh of one goines-pig and into the peritoneal carity of another. Local tenderness was produced in the thigh, but this. animals for us, made, twenty-one dass after Inoculating the peritoneal cavity, a post-mortem examination of the guineaple. The peritoneum was slightly pinker then normal, but was otherwise perfectly healtby. There was no $\in$ ffusion, no lymph, and no adheslons.

Concrusions.

1. The Bacillus $x$ we bave found to be present in about 30 per cent. of normal people.

2. The Bacillus $x$ was present in the conjunctival sac of all those patients who had neuropathic keratitis, and the organlsm could be demonstrated, together with staphylococci, among the epithelial cells at the margin of the ulcer of the excised eye.

3. In those cases which did not develop keratitis after excision of the Gasserian ganglion no $x$ bacillus was found.

4. We therefore conclude that we are justified in suspecting that the presence of the bacillus in the sac is necessary for the production of neuropathlc keratitis.

5. The presence of the $x$ bacillus, however, without an associated lesion of the Gasserian ganglion, does not lead to keratitis.

6. Mere presence of the organism in a patient whose Gasserian ganglion has been removed is not sufficient to produce neuropathic keratitis, because, if the eyelids are sewn together, the disease does not develop, or, if the condition is alresdy present, it will tend to heal rapidly aiter guture of the lids. We are, therefore, driven to conclude that there is a third necessary factor, and that this factor Is in some way prevented from acting by closure of the lids. This result of closing of the lids may be due elther to the effect on the organism or to the effect on the eye. The organlam continues, however, to live in the conjunctival sac, in splte of the closure of the lids.* . It is, of course, possible that the closure of the lids may act by diminishing the virulence of the organism and separating the lids by increasing it again to its normal level, but the facts that the effect on the keratitis of closing the eye is so prompt, and that keratitis may follow so immediately on again geparating the lids (see case of $M$. $H_{\text {. }}$ ), seem to be contrary to such an explanation.

Now, closure of the lids must act on the eye in one of two ways: Elther by affording protection to the cornea or by abolishing the recurrent friction of the lids. We are not in a position to indicate which of these modes of action is the efficient one, but it is at least suggestive to note that in one case in which the Gasserian ganglion bad been removed the patient had also facial paralysis, and, althongh he repeatedly had slight abrasions of the cornea, he never developed neuropathic keratitis. It is, however, important to add that no bacteriological examination was made, so that the case provides not more than a hint which inclines us to suspect that closure of the eyelids may act through cessation of the friction. It would be interesting to try experimentally whether mere suspension of movement of the eyelids would prevent the lesion or hasten the cure. $t$

Oar investigations, then, lead us to suspect that for the production of neuropathic keratitis three factors must be present: (1) Removal of the Gasserian ganglion; (2) the presence of the bacillus; (3) a factor of undefined nature dependent on the eyelids and removed by closing them. (1) and (2) are not adequate alone, as suture of the lids prevents or cures neuropathic keratitis; (1) and (3) are not adequate alone, becauge, as we have shown, keratitis only occurs after destructive lesions of the Gasserian ganglion

* The bacillus was found to be still present in one case after the lids had been united for three months.

$\uparrow$ Wilbrand and saenger have collected $z 0$ cases of lagophthalmos in conjunction with anaesthesia of the cornea from paralysis of the 
when the organlem is present and in the same proportion of patients as that in which the organism occurs in normal persons.

The mode of action of the first tactor is, of course, in no way e'ucidated by our investigationg.

$$
\text { REFERENCES. }
$$

1. Wilbrand and Saenger: Die Neurologie des Auges. Bd. ii. Wiesbaden, 1901 .

2. Magendíe: Suite de 3 expérience r sur les fonctions de la cinquième paire de nerfs. Journal de Physinl. Exper. et Pathol. 182t. T. iv,

3. Bernard, Claude : Lec. sır la Physiol. et Patho'. du Syst. Nerv. T. ii. 4. Gaule: Der Einfluss des

Phys. 189l. Bd. v, Nr. 15. Trigeminus auf die tornhaut. Centrabl. Hornhaut. Centralbl. f. Phys. 1891. Bd. v. Nr. 16.

6. Bernhardt: Die Erkrankungen der peripherischen Nerven, Th. 1. Wein, 1895, s. 142.

7. Erb: Krankheiten der peripher. Cerebro-spin. Nerven. Leipzig, 1876. Graefe : Neuroparalytische Hornhautaffection. Arch.f. Ophthalm. Bd. i, 1854, S. 206 .

9. Krause: Die Neuralgie den Trigeminus. Leipzig, 1896

10. Parsons: Lesions of the Trigeminal Nerve. Lancet, May 25th,

1907. Head and sherren : The Consequences of Injury of the Peripheral 11. Head and Sherren : The Consequences
Nerves in Man. Brain, pt. cx, summer, 1905 .

12. Head and Rivers: The Afferent Nervous system from a New Aspect. Brain, pt. cx, summer, 1205

13. Head and Thompson: The Grouping of $\Delta$ fferent Impulses within the Spinal Cord. Brain, pt. cxvi, vol. xxix.

14. Bayliss : On the Origin from the Bpinal Cord of the Vasodilator Fibres of the Hind Limb. Journal of Physiology, vol. Xxvi. 1901 , p. 173. Further Researches on Antidromic Physology, vol. xxwili, 190?, p. 276 .

Lancet, July 2nd, 1898

16. Samuel: Die tropischen Nerven. Leipzig, 1860. auftretenden Frnahrungsstörungen, am Auge und anderen Organen. Zeitsch. f. Rationelle Medizin, R. 3, Bd. xv, 1862, S. 254.

18. Spalitta: Arch. de Ottalmol, ii , 1894

19. Schiff: Ueber die nach Durchschneidung des Trigeminus am Auge eintretende Ernahrungsstörung. Zeitsch. f. Rationelle Medizin. R. 3, Bd. xxix, 1867, s. 217.

20. Seydel: Ein Beitrag zur Lehre der Keratitis neuroparalytica. Arch. f. Ophthal., xlviii. Abth. 1, S. 142

21. Senftleben: Ueber die Ursachen und das Wesen der nach der Vurchschneldung des Trigeminus

22 Gudden. (Auden Gesellichaften) 23. Fuden: (Aus den Gesellschaften.) Neurolog. Centralbl., iii, 477 Trigeminus Durchschneidung. Mediz. Jahrbilcher von der Qes. der Arzte, 1877, Bd. 7, 1877. S. 197

24. Hippel : Zur Aetiologie der Keratitis neuroparalytica. Arch. $f$. Ophthal., Bd. $\mathrm{Xx \times \nabla}, \mathrm{R}$ iii, s. 217.

25. Hippel: Anatomische Befunde bei eitriger Keratitis des Menschen. Arch. f. Ophthal, Bd. xlvii, 1899, 8. 157.

26. Ollendorf: Ueber die Rolle der Mikro-organismen bei der 1900 , 8. 455 .

27. Halliburton: New Eacts in Relation to the Processes of Nervous Degeneration and Regeneration. Lnn cet, 19J7, pp. 1207 and 1273.

28. Angelucci : Arch. die Ottalmol., xil, Palermo.

29. Davies: The Functions of the Trigeminal Nerve, Brain, Part cxviii, vol. Xxx, 1ऽ07.

30. Turner: The Results of Section of the Trigeminal Nerve, BRITISH MEDICAL JOORNAL, 1895, p. 1279 .

\section{A PLEA FOR THE IMPROVEMENT IN THE TEACHING AND AN ENCOURAGE- MENT IN THE STUDY OF LEGAL MEDICINE.*}

By J. J. BUIST, M.B.LOND., DIVISIONAL SURGEON TO THE CARDIFF CITY POLICE; PRESIDENT OF THE CARDIFF MEDICAL SOCIETY.

IT seems almost superfluous in these days, when so much Is said of the necessity of improved technical education, and when such rapld strides and developments are being made in the various branches of medical sclence, to have to call attention to the backward condition of one very important medical sclence.

I venture, therelore, to polnt out some of the defects of our present knowledge of the subject of forensic medicine, together with the causes of the present lack of interest in the subject, and the possible remedles for thls state of things.

It Is commonly said-nay, it is almost an accepted dictum-that medical men make bad witnesses. So far as the public may think this it does not really concern us for a moment, as they are dissatlsfied and critlcal because the medical witness is often not able to give a definite but only a speculative answer to the questions put. These, the unthinking majority, will never appreciate the

* Introductory Address delivered before the Cardiff Medical society it the opening of the session, Tuesday, October 8 th, 1907. difficult points that have to be considered in order to arrive at an accurate solution of the varlous problem presented. In fact, It is often rather creditable to the medical witness that he is guarded in his replles than that he should endeavour to give precise answers at the expense of truth and justice. Of course the criticism of medical evidence has become more acute of late, since the amount of litigation produced by recent enactments has bronght such $a$ mass of conflicting evidence into the civll courts. But I wish to speak more particularly of the medical witness in relation to criminal cases. In this direction I think we shall have to concede that, after making due allowance for the criticism of the unthinking and aneducated the value and status of the medical witness will bear a deal of improvement. Whllst making this admisslon; I think that I can show, in pointing out the causes of the backward condition of the study of the subject of forenslc medicine, that no reflection is implied upon the skill or ability of the various members of the profession who testify in the courts. In If $c^{\prime}$, in some cases our most eminent surgeons and physiclans mike the weakest witnesses. But rather the medical witne ss suffers from a lack of opportunity belng afforded hlm in our system of education, and in the failure of the State to do its part in making provision for a number of skilled medicc-legal experts.

What, now, are the causes of the condition to which I have just referred? I think they can be divided Into two main classes, namely, defective teaching and a lack of material, together with a want of support on the part of the :State.

In the first place, our teaching is defective because we have not in our medical schools lecturers who are specially qualified to teach the subject. There are, I admit, several brillant exceptions, but in most cases the gentleman who is appointed to teach the eubject has usually distinguished himself in surgery or medicine, or he is the next one who is entitled to 8 post on the teaching staff. Thls calls to my mind the remarks of $\mathrm{Mr}$. Lynn Thomas when delivering his presidential address two years ago. He called attention to the fact that up till quite recently the gentleman who was a surgeon on the staff of the Cardiff Infirmary suddenly blossomed forth into the dignified position of a physician, by reason of senlortty, on the resignation, retirement, or death of a colleague who had been a physician. I remember how 1 he alluston drew forth the smiles of the members. Now I maintsin that the ides of a surgeon or physician being appointed a lecturer on forensic medlcine at a medical school simply becsuse it is his turn to get the next post, is equally a matter of amusement. Would we appoint as lecturer on medicine or eurgery, even at the smallest provinclal school nowadays, one who is a general practltloner? Would we appoint as lecturer on gynaecology one who has not devoted some considerable time to speclal study and practlce of diseases of women? Yet we find that in a number of schools gentlemen are appointed as lecturers on forensic medicine-eminent physiclans or surgeons no doubt--who have little or no experience of practical character in the subject which they are expected to teach. It mav be sald that the number of gentlemen so qualified and experienced is very limited. That I readlly admit, and will deal with this dearth of speclally qualified medical jurists when I come to the second cause, lack of material together with a want of support on the part of the State.

Secondly, the lectures are, generally gpeaking, not made interesting and attractive, and little inducement is held out to the students to pay more than a cursory attention to the subject. The consequence is that the student attencls just snfficiently often to get signed up for his examination, and learns just enough to scrape through.

Thirdly, the course of lectures is defective in not providing for some instruction on legal procedure, and some explanation of certain legal definitions, as well as an elementary course in the law of evidence and criminal law. There are many, I have no doubt, who would join Issue with me on this point, but I consider that this is of the greatest importance if the medical witness is to command a greater respect in our courts. In my experlence, one of the greatest reasons that the medlcal witness fails to do himself justice :Is not that he is unintelligent or unskilfal; but that he fails to thoroughly appreclate his 